Despite government assurances, some patients - and some doctors - feel that personal and potentially sensitive information will not be secure in a centralized, national database. And last week, concerned that patients were not yet fully aware of the system, the British Medical Association called for a halt to the SCR roll-out. It argued that the speed with which the database is being introduced means that patients do not necessarily know about it and that even those who do could not easily exercise their right to opt out of having an SCR.

Those criticisms are well taken. The Department of Health insists that it supports the right of any patient to opt out, and denies that it is rushing implementation of the system. But the roll-out is occurring before an evaluation of the SCR scheme by University College London (UCL) has even been published - and thus before the results of changes made following issues with patient consent raised in a previous UCL evaluation are public. As a result, public confidence in the deployment of the system is at risk of being seriously undermined.
Governments are right to be enthusiastic about such databases, but wrong to rush ahead before they have laid the groundwork for public understanding and trust. This is especially important given that pharmaceutical companies are increasingly showing an interest in the potential of electronic records. Although there is nothing in principle wrong with such use of data, it is easy to see how the public might be suspicious of corporations potentially profiting from highly personal information.

The UK government should suspend the SCR roll-out, at least until UCL's second evaluation is published next month and it is clear that previous concerns have been addressed. It should also ensure that all patients have a clear explanation of the system as well as ready access to the form needed for them to opt out.

For now, the scant data to be held in the UK database will be of limited use to researchers. But those wishing to tap into the potentially rich resources of its successors should work to ensure that the process of medical data collection is not only secure, ethical and beneficial to all concerned, but that it is seen to be so.

\section{Setting the bar}

\section{Europe's chief science adviser must be given authority and support to deliver across the board.}

urope is well on its way to appointing its first chief scientific adviser. European Commission president José Manuel Barroso set the ball rolling last September, when he pledged to create the position to fill a gaping lack of rigorous, independent scientific input into European policy-making. Europe's newly elected commissioners kept up the momentum by officially creating the position at a meeting on 17 February — remarkably quick action by commission standards, indicating that the issue is being taken seriously.

And last week, Nature has learned, the as-yet-unfilled position dodged a bullet. Some commission officials had been pushing to bury the science adviser's office deep within the bureaucracy, making it all but certain that the future incumbent would lack sufficient power and independence to be successful. But the commission has now rejected that suggestion, making it clear that the chief scientist will report directly to Barroso, and will have a high enough status in the commission to make decisions without interference.

Further details of the chief scientist's remit are still under discussion. But the early indications are that the chief scientist will be involved mainly in delivering science advice for sound policy-making across the board - in issues such as climate change and energy, for example - and will not have only a narrow focus on policies for research funding. It also seems that the chief scientist will receive administrative assistance from the Bureau of European Policy Advisers, a kind of official government think-tank close to the commission president - a move that should further help guarantee the chief scientist's access to Barroso.

These developments are encouraging. Until now, the Bureau of European Policy Advisers has rarely given sufficient weight to science in decision-making, concerning itself primarily with economic matters. The resulting dearth of scientific input has contributed to a number of ill-considered commission policies, most notably its infamously harsh stance against genetically modified organisms. It will be the job of Europe's chief scientist to turn this around.

However, more is needed to ensure that the chief scientist will be able to deliver. Any chief scientist is forced to walk a fine line between remaining independent of political interference and maintaining the trust and goodwill of the officials he or she is advising. The difficulties inherent in so doing were highlighted by the recent sacking of David Nutt, an adviser on drugs policy to the British government, on the grounds that his academic work seemed to contradict government policy on illegal substances. To ensure that European policy receives the independent science advice it needs, the commission "The issues are much too complex and wide-ranging for any one individual to master."

should draw up principles to which they and the adviser must adhere, in a similar vein to the guidelines the British government is developing in the wake of the Nutt affair.

In addition, Europe's chief scientist cannot be a one-person show. The issues that he or she will have to address are much too complex and wide-ranging for any one individual to master. John Holdren, science adviser to US President Barack Obama, heads an Office of Science and Technology Policy that comprises more than 70 scientists, analysts and administrators. A similar team of dedicated experts should be created for the European science adviser, because the resources available from the Bureau of European Policy Advisers, which currently lacks scientific expertise, are unlikely to be sufficient.

Barroso will nominate his chief science adviser in the near future. It is crucial that this important position starts out on the right foot and is filled on the basis of scientific credibility. Allowing politics to interfere, as can so often happen in Europe, will destroy the authority of the chief scientist and waste a valuable opportunity. 